\title{
Recombinant follitropin alfa/lutropin alfa in fertility treatment
}

\author{
This article was published in the following Dove Press journal: \\ Biologics:Targets \& Therapy \\ 22 December 2009 \\ Number of times this article has been viewed
}

\section{Ahmed Gibreel' Siladitya Bhattacharya ${ }^{2}$ \\ 'School of Medicine and Dentistry, University of Aberdeen; ${ }^{2}$ Aberdeen Maternity Hospital, Aberdeen, UK}

Correspondence: Siladitya Bhattacharya Professor of Reproductive Medicine, School of Medicine and Dentistry, University of Aberdeen, Aberdeen Maternity Hospital, Foresterhill, Aberdeen AB25 2ZD, UK

Tel +44 I224550590

Fax +44 I224559948

Email s.bhattacharya@abdn.ac.uk
Abstract: Recombinant human follicle stimulating hormone (rFSH) and luteinizing hormone (LH), also known as follitropin alpha and lutropin alpha, are manufactured by genetic engineering techniques which ensure high quality and batch to batch consistency. Follitropin alpha can be used for controlled ovarian hyperstimulation in assisted reproduction, ovulation induction for WHO group I and II anovulatory infertility and in men with hypogonadotrophic hypogonadism $(\mathrm{HH})$ or idiopathic oligo-asthenospermia. Current evidence suggests superiority of urinary human menopausal gonadotropin (HMG) over follitropin alpha in controlled ovarian hyperstimulation for IVF in terms of live birth rate per couple. Addition of lutropin to follitropin alpha in an unselected IVF population does not appear to confer any benefit; however, it may have a role in ovulation induction in women with hypothalamic hypogonadism. Urinary HMG preparations (especially currently available highly purified preparations) are more cost effective than $\mathrm{rFSH}$ in terms of cost per ongoing pregnancy. However, women using rFSH injection pen devices have higher levels of satisfaction as compared to those using urinary HMG by means of conventional syringes.

Keywords: infertility, follicle stimulating hormone, luteinizing hormone, follitropin alpha, lutropin alpha, in-vitro fertilization, urinary gonadotrophins

\section{Introduction}

The pivotal role of the pituitary gland in reproductive function was established in the 20th century, when it became clear that it secreted two key hormones - follicle stimulating hormone (FSH) and luteinizing hormone ( $\mathrm{LH}) .{ }^{1,2}$ This discovery allowed clinicians to treat infertile couples by means of pituitary extracts. ${ }^{2,3}$ Animal pituitary extracts of follicle stimulating hormone (FSH) were the first commercially available gonadotropins in the 1930s while the first use of cadaveric human gonadotropins for induction of ovulation was reported in $1958 . .^{4,5}$ Human pituitary gonadotropins (HPG) continued to be used in clinical practice for a number of decades before being withdrawn following reports of an association between its use and cases of CreutzfeldJakob disease (CJD). ${ }^{5-7}$ Meanwhile, increasing demands for gonadotropins, which could not be met from cadaver specimens, led to the extraction and isolation of human menopausal gonadotropin (HMG) from urine in 1950. ${ }^{3}$ Human menopausal preparations contain both FSH and LH activity in a ratio of 1:1, though some of the LH activity was achieved by addition of human chorionic gonadotropin (HCG). ${ }^{8,9}$ Subsequently the development of advanced immunopurification and fractionation techniques using specific monoclonal antibodies led to the introduction of highly purified urinary preparations. ${ }^{3,5,10,11}$ More recently, use of genetic engineering technology led to the

submit your manuscript | www.dovepress.con 
development of the recombinant human gonadotropins preparations. ${ }^{12,13}$ Follitropin alpha was the world's first recombinant human $\mathrm{FSH}$ preparation and lutropin alpha the first recombinant human luteinizing hormone (LH). ${ }^{14,15}$ A mixture of follitropin alpha and lutropin alpha (follitropin alpha/lutropin alpha 150 IU/75 IU) has been recently commercially available in a single product called Pergoveris ${ }^{\mathrm{TM}}$ (Merck Serono). ${ }^{16}$ Biopatency studies have confirmed that the new drug is treated in the body similarly as if each product were administered separately. ${ }^{14,16}$ This combination could be of value for the stimulation of follicular development in infertile women with severe endogenous $\mathrm{FSH}$ and $\mathrm{LH}$ deficiency, using a single daily injection. ${ }^{17}$

\section{Pharmacology}

\section{Structure}

Follitropin alpha and lutropin alpha are glycoproteins which are structurally similar to endogenous FSH and LH. They possess similar alpha but different specific beta subunits. ${ }^{18,19}$ The nomenclature "alpha" differentiates it from another recombinant human FSH product which was marketed later as follitropin beta. ${ }^{20}$

\section{Isoforms}

Endogenous gonadotropins exist in a number of different isoforms which have similar amino acid sequences but differ in their terminal silaic acid content. ${ }^{21-24}$ Different isoforms can vary in their biophysical characters; but their clinical roles have yet to be determined. ${ }^{19,25,26}$ An isoform isolated at any particular time in the human body can be affected by gender, age, source of the sample, endocrine state and phase of menstrual cycle. ${ }^{27-29}$ Follitropin alpha is similar to the natural FSH isoform detected at mid cycle while Follitropin beta resembles that detected in the early follicular phase. ${ }^{30}$ Recombinant FSH preparations differ from urinary $\mathrm{HMG}$ in their silaic acid content and have a shorter half life as they are more basic. ${ }^{9,31}$ Currently, lutropin alpha is the only commercially available recombinant LH preparation with a consistent isoform profile. ${ }^{32}$

\section{Biological and specific activity}

Biological activity of an agent is related to its effect on living tissue while specific activity represents its activity per unit mass. Follitropin alpha has a specific activity of 10,000 IU/mg which is similar to the urinary highly purified urofollitropin but is 100 times higher than that of other urinary derived FSH products. ${ }^{8,33}$ Follitropin alpha has been shown to induce follicular growth on its own without the addition of $\mathrm{LH}$ in most cases. ${ }^{34,35}$ However, the role of LH for optimal follicular development has been recently described - especially in profoundly LH deficient women with hypogonadotrophic hypogonadism. ${ }^{36,37}$ Although a minimum level of serum LH is required for optimum growth, excess LH can cause follicular growth arrest and prevent growing follicles from reaching the late antral stage. ${ }^{38,39}$ Follitropin alpha administration has been associated with a significant increase in serum levels of estradiol level, inhibin A and inhibin B. ${ }^{40,41}$ Significant increases in follicular levels of insulin and growth hormone have been detected in follitropin stimulated women. ${ }^{20}$

\section{Pharmacokinetics}

The pharmacokinetic properties of follitropin alpha and lutropin alpha are similar to those of urinary derived FSH and $\mathrm{LH}$, respectively. ${ }^{20,42}$ Both are eliminated by means of the liver and kidney. ${ }^{42,43}$ Although subcutaneous (SC) administration is recommended, both products can also be administrated by the intramuscular route (IM). ${ }^{7,44}$ Subcutaneous administration had been found to produce shorter absorption half life and time to maximum plasma concentration. Following a single subcutaneous 150 IU dose, follitropin alpha has a terminal half-life of about 37 hours, bioavailability of $74 \%$, mean peak serum drug concentration $\left(\mathrm{C}_{\max }\right) 3 \mathrm{IU} / \mathrm{L}$ and the time to maximum plasma concentration $\left(\mathrm{t}_{\max }\right)$ was 16 hours. $^{45}$

Lutropin alpha has a one compartment first-order process. ${ }^{42}$ Following subcutaneous administration of $150 \mathrm{IU}$ lutropin alpha, a mean $\mathrm{C}_{\max }$ of $1.1 \mathrm{IU} / \mathrm{L}$ is reached after 6 hours $\left(\mathrm{t}_{\max }\right) \cdot{ }^{42}$ Lutropin alpha has a terminal half-life of about 18 hours and a bioavailability of 56\% (following a single subcutaneous 10,000 IU dose). ${ }^{44}$

\section{Manufacturing}

Both follitropin alpha and lutropin alpha are manufactured by recombinant DNA technology. ${ }^{12,32}$ The gene encoded for the bio formation of each hormone is incorporated into a genetically engineered Chinese hamster cell line. ${ }^{20,46}$ The products of this cell line are then extracted and purified by means of a series of immunochromatograpic techniques. ${ }^{46,47}$ which help to maintain quality assurance and batch to batch consistency. ${ }^{3,48,49}$ The current manufacturing process permits the follitropin alpha active ingredient to be quantified by its protein content (mass in $\mu \mathrm{g}$ ); a technique called filled by mass $(\mathrm{FbM})$ rather than the conventional method which relied on a product's biological activity (bioassay). ${ }^{50,51}$ It has been suggested that the use of follitropin alpha filled by mass (FbM) may lead to more consistent ovarian stimulation, 
less need to dose adjustment and fewer cycle cancellations. ${ }^{51,52}$ The biological activity of lutropin alpha is determined by bioassay. ${ }^{53}$

\section{Safety}

\section{General}

Clinical trials have shown that follitropin alpha and lutropin alpha are very well-tolerated by patients. Ovarian hyperstimulation syndrome and multiple pregnancy are the most serious side-effects linked to gonadotropin use. ${ }^{54}$ Recombinant FSH is not believed to increase the risk of miscarriage. ${ }^{55}$ No fetal effects had been reported after accidental first trimester exposure to follitropin alpha. ${ }^{56}$ Headache, nausea, abdominal pain, breast pain, ovarian cyst formation are the most common side-effects of both follitropin alpha and lutropin alpha, while ovarian hyperstimulation is a serious, albeit rare side-effect. ${ }^{57}$

Side effects have been reported in $46.5 \%$ of patients who used follitropin alpha alone and 42.4\% women receiving follitropin alpha/lutropin alpha. These include headache, nausea, mastalgia, fatigue, abdominal pain and development of functional ovarian cysts. . $^{620,33,53,57-59}$

A case report has described subclavian deep vein thrombosis and mild ovarian hyperstimulation associated with treatment with recombinant $\mathrm{FSH} .{ }^{60}$ Bar et al have suggested diminished platelet aggregation in women using urinary FSH compared to $\mathrm{rFSH} .{ }^{61}$ Local skin reaction including mild irritation, pain, erythema and pruritus has been reported in $1.8 \%$ of a total of 1093 follitropin alpha injections. ${ }^{62}$ Subcutaneous injection of lutropin alpha was not associated with any adverse local skin reactions in almost $90 \%$ of the injected cases ${ }^{36}$ only $3.4 \%$ women reported anything more than a mild skin reaction after SC injections with recombinant LH. ${ }^{37}$ No antibodies to follitropin alpha have been discovered in women receiving any of these preparations..$^{33,37,57}$ There were two case reports describing two separate IVF cycles where follitropin alpha was used successfully in inducing follicular growth in the absence of any allergic reactions in two women with severe allergic reactions to urinary FSH. ${ }^{63,64}$ Data from randomized trials and case series suggest that follitropin alpha is associated with better local tolerance and fewer injection site side effects than follitropin beta. ${ }^{65-67}$

\section{OHSS}

Severe ovarian hyperstimulation syndrome (OHSS) is a serious and a life-threatening complication with an incidence of about $0.5 \%$ to $2 \%{ }^{68,69}$ Polycystic ovarian syndrome (PCOS), previous episodes of OHSS and high doses of exogenous gonadotropins are known to increase the risk of developing OHSS. ${ }^{70-72}$ There is some evidence that individual sensitivity to FSH stimulation may be more important than the total amount of gonadotropins used..$^{73}$ The incidence of OHSS in women in women using recombinant FSH in IVF treatment has been reported in two recent systematic reviews to range between $0 \%$ to $4.6 \%$ when $\mathrm{rFSH}$ was used for controlled ovarian hyperstimulation $(\mathrm{COH})$ in IVF. ${ }^{74-76}$ The overall incidence was $2.6 \%$ after pooling results from 9 studies including a total of 1454 women in the rFSH group. ${ }^{68}$ There was no difference in the rate of OHSS between women on rFSH versus urinary FSH. ${ }^{77,78}$

After pooling results from 4 randomized trials including 381 participants undergoing IVF in GnRH agonist down regulated cycles, the reported incidence of OHSS was $2.8 \%$ when lutropin alpha was co-administrated with rFSH. $^{79}$

Table I Classification of disorders of ovulation

\begin{tabular}{llll}
\hline Group & Description & Site of the lesion & Hormone concentration \\
\hline WHO & Hypogonadotrophic & Contral & Low FSH \\
type I & Hypo-estrogenic & Normal prolactin \\
WhHO & Normoprolactinemic & & Normal FSH \\
type II & Hypogonadotrophic & Hypothalamic-pituitary & Normal estradiol \\
& Normo-estrogenic & ovarian axis & Normal prolactin \\
WHO & Normoprolactinemic & & High FSH \\
type III & Hypergonadotrophic & Ovarian failure & Low estradiol \\
& Hypo-estrogenic & & Normal prolactin \\
Hyperprolactinemic & Normoprolactinemic & & Normal FSH \\
& Hyperprolactinemic & Central & Normal estradiol \\
\hline
\end{tabular}

Adapted with permission from Shetty A. Disorders of ovulation. In:Templeton AA. ed. Management of Infertility for the MRCOG and Beyond. London: RCOG press; $2001 .{ }^{161}$ Copyright (C) 200I RCOG Press.

Abbreviation: $\mathrm{FSH}$, follicle stimulating hormone. 
There was no difference in the incidence of OHSS between women who received $\mathrm{rLH}$ plus $\mathrm{rFSH}$ and those who received rFSH alone. ${ }^{79}$

\section{Multiple pregnancy}

Gonadotropin stimulation of the ovaries in assisted reproduction leads to multifollicular growth. ${ }^{80,81}$ Unlike IVF, where the number of embryos replaced determines the incidence of multiple gestations,${ }^{81}$ the release of more than one oocyte in ovulation induction or superovulation with IUI could potentially increase chances of multiple pregnancy. ${ }^{82}$ Phase III trials of follitropin alpha show a multiple birth rate of $20 \%$ when the drug is used for ovulation induction and $35 \%$ when it is used in IVF. ${ }^{53}$

A number of different strategies have been proposed to decrease the chance of multiple births after ovulation induction but their impact has been limited. ${ }^{54}$ The two systematic reviews of trials comparing rFSH to urinary HMG in IVF showed no difference in multiple pregnancy rates between the two treatment groups. ${ }^{77,78}$

\section{Clinical efficacy}

FSH and LH have significant roles in ovarian follicle differentiation, selection and survival. ${ }^{83}$ Exogenous gonadotropin administration has been suggested as an effective means of treatment in WHO group I and II anovulation, and in males with hypogonadotrophic hypogonadism..$^{59,84,85}$ In normogonadotropic women, $\mathrm{COH}$ is an essential prerequisite for successful in vitro fertilization (IVF) treatment. ${ }^{86}$ The aim in IVF is to stimulate multiple follicular growth in order to enhance the increase the yield of oocytes. ${ }^{87}$ Superovulation is also used in conjunction with intrauterine insemination even in absence of evidence of anovulation, though the rationale for this intervention has been challenged recently. ${ }^{88,89}$

Different protocols for $\mathrm{COH}$ had been described. In IVF, these protocols usually involve pituitary suppression by GnRH agonists or antagonists. ${ }^{90-92}$ Variable long, short or ultrashort protocols for GnRH agonists have been suggested. ${ }^{90,93}$ The commonest is the long luteal phase protocol where GnRH agonists are started in the luteal phase of the cycle preceding the IVF cycle..$^{94,95}$

\section{Efficacy in IVF/ICSI}

Follitropin alpha

Recently, two systematic reviews of randomized trials comparing recombinant FSH ( $\mathrm{rFSH})$ and urinary HMG (uHMG) in unselected subfertile women undergoing
IVF/ICSI (intracytoplasmic sperm injection of eggs), have been published..$^{77,78}$

In the first, results from a meta-analysis of 12 randomized controlled trials (RCTs), with a total of 2937 participants have shown an overall live birth rate of $21.8 \%$ in the $\mathrm{rFSH}$ group compared to $24.9 \%$ in the uHMG group. ${ }^{77}$ The second systematic review included only 7 RCTs which compared $\mathrm{rFSH}$ and HMG in IVF cycles where a long pituitary downregulation protocol was used. ${ }^{78}$ The pooled results based on a total of 1259 women showed that the live birth rate per woman treated with $\mathrm{rFSH}$ was $21.6 \%$ compared to $25.4 \%$ in the HMG group (Figure 1). ${ }^{78}$

Al-Inany et $\mathrm{al}^{77}$ found live birth rate per woman in the HMG group to be significantly higher than in the $\mathrm{rFSH}$ group (odds ratio [OR] 1.20, 95\% confidence interval [CI] 1.01 to 1.42$).{ }^{77}$ Coomarasamy et al ${ }^{78}$ showed live birth rate per woman in the $\mathrm{UHMG}$ group to be significantly higher than the rFSH group (OR 1.18, 95\% CI 1.02 to 1.38 ). ${ }^{78}$ These results are based on a general population of women undergoing IVF. It has been suggested that specific groups of patients such as older women or poor responders might benefit from $\mathrm{rFSH} .{ }^{96,97}$ However, there is a need for relevant evaluative studies in order to elucidate the role of $\mathrm{rFSH}$ in those women. Neither systematic review has shown any differences in rates of multiple pregnancy rates, ovarian hyperstimulation or miscarriage. ${ }^{77,78}$ Unlike Coomarasamy and his colleagues, Al-Inany et al reported a significant reduction in dose and duration of stimulation and available embryos in the rFSH group. ${ }^{77}$

Traditional uHMG preparations contained FSH and LH in a ratio of $1: 1$, while more recent highly purified $\mathrm{FSH}$ (HP FSH) products using monoclonal antibody techniques for extraction and purification of FSH contain negligible amounts of $\mathrm{LH}(P<0.001 \%) .{ }^{8}$ In their systematic review, ${ }^{77}$ Al-Inany et al examined the effect of the type of HMG (purified versus conventional) compared with $\mathrm{rFSH}$ on IVF outcome. They performed a subgroup analysis to compare HP HMG with rFSH and showed a similar outcomes in the HP-HMG group in terms of live birth rate (OR 1.21, 95\% CI 1.02 to 1.44 ) and clinical pregnancy rate (OR 1.26, 95\% CI 1.04 to 1.53$).{ }^{77}$ Two recent RCTs, one using a long downregulation protocol along with a GnRH agonist and the other a GnRH antagonist, failed to demonstrate any significant difference in pregnancy rates between HPFSH and $\mathrm{rFSH} .{ }^{98,99}$

Follitropin alpha and follitropin beta represent two isoforms of the same molecule. ${ }^{20}$ Although some authors have suggested a difference in clinical efficacy between the two 
molecules, ${ }^{13,100}$ live birth rates and clinical pregnancy rates have been shown to be comparable in four randomized controlled trials. ${ }^{65,101-103}$

\section{Lutropin alpha in IVF}

It has been reported that high LH levels in the follicular phase of the IVF cycle could have a detrimental effect on the outcome of IVF ${ }^{104,105}$ but a minimum threshold serum concentration of $\mathrm{LH}$ is required for optimum folliculogenesis. ${ }^{38}$ According to Loumaye and colleagues, the effect of LH on the growing cohort of follicles demonstrates a ceiling effect and exceeding a certain threshold can compromise follicular development. ${ }^{38}$

Results of a recent Cochrane review do not confirm an increase in live birth rates associated with the addition of rLH to rFSH in GnRH agonist downregulated IVF cycles compared to rFSH only stimulated cycles (two trials: OR $1.51,95 \%$ CI 0.79 to 2.87$){ }^{79}$

Meta-analyses of RCTs where GnRH antagonists (rather than GnRH agonist) were used for pituitary suppression also failed to find any significant differences in terms of clinical pregnancy rates, as none of the studies included reported live birth. ${ }^{79}$

There was no difference in the risk of early miscarriage between women on rFSH who were co-treated with $\mathrm{rLH}$ (eight trials: OR $0.59,95 \%$ CI 0.35 to 1.02 ) compared to women who were treated with $\mathrm{rFSH}$ alone. ${ }^{79}$ However, after exclusion of a single trial that used a flare up GnRH protocol, a trend towards reduced miscarriage rates (of borderline significance) was found in women co-treated $\mathrm{rLH}$ (seven trials: OR $0.57,95 \%$ CI 0.33 to 1.00 ). There was a significant difference in live birth rate in favor of rLH supplementation in poor responders (three trials: OR 1.85, 95\% CI 1.10 to 3.11 ). There were no differences in other IVF outcomes such as OHSS, number of oocytes retrieved, amount of rFSH used, serum estradiol level on the day of HCG administration and miscarriage rate. ${ }^{79}$

These findings are in accordance with results from a previous meta-analysis of results from 4 RCTs examining the effect of adding rLH to rFSH in GnRH agonist downregulated IVF cycles. ${ }^{106}$

An RCT which included 84 participants found no significant difference in pregnancy rate between poor responders treated with either rFSH alone or rLH and FSH in an GnRH agonist flare up protocol. ${ }^{107}$

In a systematic review where trials using GnRH agonists and antagonist cycles were pooled, live birth rates and clinical pregnancy rates were similar regardless of whetherrLH was co-administrated with rFSH or not. ${ }^{108}$
Although some clinicians have reported that $\mathrm{rLH}$ administration prior to rFSH in IVF cycles increased the number of antral follicles, this did not translate into improved rates of live birth pregnancy. ${ }^{109}$ Thus, there is no evidence at the present time that co-administration of $\mathrm{rLH}$ to $\mathrm{rFSH}$, in controlled ovarian hyperstimulation for IVF, has a beneficial effect in IVF.

In the European Union, a combination of follitropin alpha and lutropin alpha (Pergoveris ${ }^{\mathrm{TM}}$ ) is currently available for single subcutaneous injection. ${ }^{17}$ The ratio of follitropin alpha to lutropin alpha in that preparation is $2: 1$, respectively. A randomized crossover trial had demonstrated bioequivalence between follitropin alpha and lutropin alpha administered alone or in this fixed 2:1 combination. ${ }^{110}$

\section{Use of follitropin alpha in ovulation induction Hypogonadotrophic hypogonadism}

WHO group I anovulation is a rare condition that can be caused by a hypothalamic or pituitary defect due to congenital or acquired causes (Table 1). ${ }^{11}$ Management options include exogenous replacement of gonadotropins and pulsatile $\mathrm{GnRH}$ agonist administration. ${ }^{112}$ In women with intact pituitary function, pulsatile gonadotropin releasing hormone (GnRH) therapy can be used. ${ }^{113}$ The advantages of pulsatile GnRH compared with gonadotropins are that there is a lower risk of hyperstimulation and multiple pregnancies and the need for monitoring is minimal. ${ }^{36}$ Exogenous gonadotropins administration is the alternative therapeutic option in hypothalamic dysfunction and the first line treatment if the defect is primary pituitary failure. ${ }^{113,114}$

Currently available evidence indicates that $\mathrm{rFSH}$ alone may not be sufficient to promote optimum follicular growth in severely gonadotropin deficient women. ${ }^{37}$ It has been suggested that a minimum threshold of serum $\mathrm{LH}$ is required to re-establish meiosis and final stages of growth of antral follicles. Meanwhile, follicular growth arrest might occur, should LH exceed that threshold, in what is called an LH ceiling. Antral follicle growth arrest (at $10 \mathrm{~mm}$ diameter) has been observed in $\mathrm{LH}$ deficient cycles. $^{38}$

A dose finding trial included 38 WHO type I anovulatory patients, who were randomly assigned to receive either 0 , 25,75 , or $225 \mathrm{IU}$ rLH once daily in addition to $150 \mathrm{IU}$ follitropin alpha once daily for up to 20 days. None of the 8 patients who received follitropin alpha alone ovulated in the absence of rLH. Fourteen percent of patients who received follitropin alpha and $25 \mathrm{IU} / \mathrm{L}$ rLH ovulated compared to 
$66 \%$ and $80 \%$ of those who received $75 \mathrm{IU} / \mathrm{L}$ and $225 \%$, respectively. ${ }^{37}$ Significant dose dependent increases in the rate of optimal follicular growth were observed in women receiving follitropin alpha with different doses of rLH varying from 0 to $225 \mathrm{IU} /$ day. ${ }^{37,84}$ Another randomized trial has shown significantly higher rates of optimum follicular growth in severely deficient LH women taking follitropin alpha plus lutropin alpha than those who were taking follitropin alpha with placebo. ${ }^{115} \mathrm{~A}$ case series from Spain included 38 hypogonadotrophic anovulatory (WHO group I) women undergoing 84 ovulation induction cycles where patients received $150 \mathrm{IU} /$ day $\mathrm{rFSH}$ and $75 \mathrm{IU} /$ day rLH. Sufficient follicular growth was observed in 79 (94\%) out of 84 initiated cycles. The $75 \mathrm{IU}$ rLH dose was found to be effective in $94 \%$ of the treatment cycles. ${ }^{36}$ The cumulative pregnancy rate following three cycles of stimulation with follitropin alpha and lutropin alpha was $39.5 \%{ }^{36}$ Clinical pregnancy occurred in 16 out of the 31 women received lutropin alpha with follitropin alpha in an extension phase of the randomized trial published by O'Dea et al in 2000 on severely hypogonadotrophic women. ${ }^{116}$ Two case reports documented pregnancies in 2 women with Kallman syndrome (amenorrhea, anosmia and hypogonadotrophic hypogonadism) and empty sella syndrome who received follitropin alpha and rLH. ${ }^{117,118}$

\section{WHO group II anovulation}

It had been estimated that $90 \%$ of women in women in WHO type II anovulation would be expected to have polycystic ovarian syndrome (PCOS). ${ }^{119}$ According to the Rotterdam consensus criteria, PCOS should be considered when two of three features are diagnosed; ovarian dysfunction, features of hyperandrogenism (clinical or biochemical) and PCO morphology. ${ }^{120}$ Although serum LH is not included as a diagnostic feature, the large majority of women with PCOS would have excess elevated LH concentrations when measured at the appropriate time. ${ }^{121}$ This may justify the potential advantages in preparations devoid of LH activity as follitropin alpha. Currently, there is no role of lutropin alpha in the management of women with PCOS.

The first baby born after ovulation induction by follitropin in a clomiphene resistant PCOS patient was reported in 1992. ${ }^{122}$ Randomized trials comparing follitropin alpha to other gonadotropins preparation or other ovulatory medications, in infertile women with WHO type II anovulation, have reported a live birth rate of $17 \%$ to $20 \%{ }^{59,123,124}$ The rate of successful ovulation has been reported to be between $57 \%$ and $85 \% .^{33,125-127}$ The pooled ovulation rate per cycle after $\mathrm{rFSH}$ in clomiphene citrate resistant PCOS women has been calculated to be $71 \%$ in a Cochrane review (Figure 2). ${ }^{128}$ Recent randomized trials have reported higher ovulation rates from $85 \%$ and up to $97 \%$ in this group of women..$^{59,103,127}$ with comparable clinical pregnancy rates per woman ranging from $17 \%$ to $20 \%$ after one cycle, ${ }^{59,103,126}$ and a cumulative clinical pregnancy rate per woman of $42 \% .{ }^{128} \mathrm{~A}$ similar cumulative live birth rate of $43 \%$ was reported by a subsequent RCT. ${ }^{129}$

There were no significant differences in ovulation rates, pregnancy rates or live birth rates between follitropin alpha and highly purified $\mathrm{FSH}^{59,103,125}$ However, a small RCT showed more favorable pregnancy rates with rFSH compared to urinary FSH. ${ }^{130}$ Two protocols have been suggested for ovulation induction with gonadotropins in this group of patients. ${ }^{131}$ In the step-up protocol the FSH dose is increased by $\leq 75$ IU every 5 to 7 days, while in the low-dose regimen, it is administrated at a low dose for 14 days followed by small incremental dose increases (when necessary), at intervals not shorter than 7 days, until follicular development is initiated. ${ }^{66,12,132}$ The type of the protocol, has not been shown to affect ovulation or pregnancy rates in studies using follitropin alpha. ${ }^{59,62}$ However, the low dose protocol significantly reduces the incidence of OHSS and multiple pregnancy. ${ }^{69,132}$

\section{Male subfertility}

FSH and LH are gonadotropins and have an important role in the process of spermatogenesis, though the actual mechanism of action is poorly understood. ${ }^{133} \mathrm{LH}$ may stimulate testosterone secretion from the Leydig cells of the testicle, while FSH stimulates Sertoli cells to facilitate germ cell differentiation. ${ }^{134}$ Follitropin alpha alone or with human chorionic gonadotropin (HCG) had been used to improve sperm parameters in male factor infertility. ${ }^{135}$ A Cochrane review included RCTs that compared pregnancy rates (spontaneous and after ART) following treatment of couples with idiopathic male factor infertility with urinary or recombinant gonadotropins (compared to placebo or no treatment), showed a significantly higher spontaneous pregnancy rate per couple randomized within three months of completing gonadotropin therapy (OR 4.17, 95\% CI 1.30 to 7.09 ). However, there were only three trials with a total of 234 participants and the authors concluded that more studies were needed to confirm this finding. ${ }^{133}$ The two RCTs included in this meta-analysis, where follitropin alpha was administered, showed no significant difference 


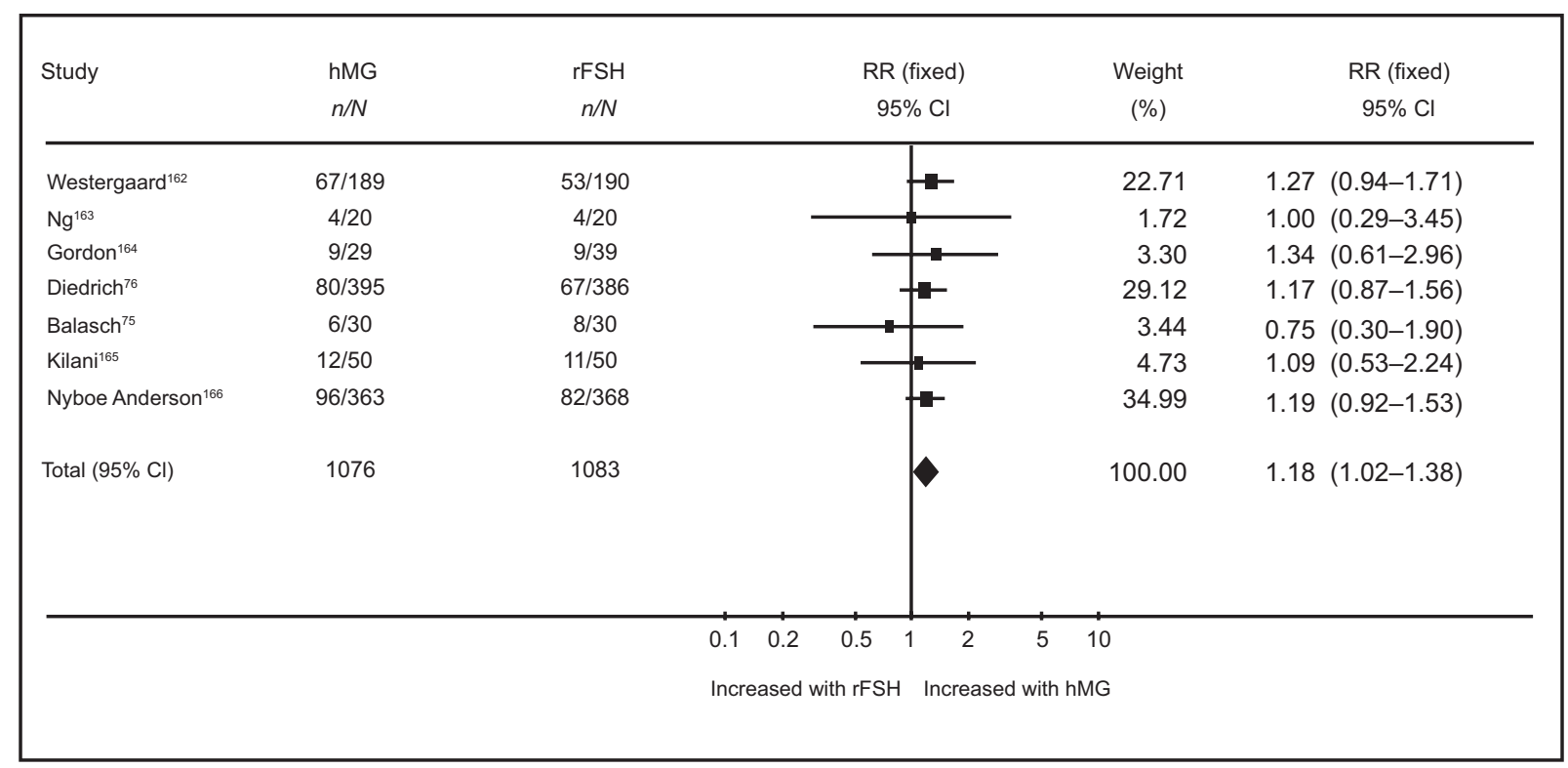

Test for heterogeneity (Chi-square test): $P=0.97$.

Test for overall effect: $P=0.03$.

Figure I Meta-analysis of randomized trials of hMG versus rFSH following a long down-regulation protocol for the outcome of live births. Adapted with permission from Coomarasamy A, Afnan M, Cheema D, van derVeen F, Bossuyt PM, van Wely M. Urinary hMG versus recombinant FSH for controlled ovarian hyperstimulation following an agonist long down-regulation protocol in IVF or ICSI treatment: a systematic review and meta-analysis. Hum Reprod. 2008;23(2):310-315. ${ }^{78}$ Copyright @ 2008 Oxford University Press. Abbreviations: HMG, human menopausal gonadotropin; RFSH, recombinant follicle stimulating hormone.

in pregnancy rates between groups which received $\mathrm{rFSH}$ injections compared to those which received placebo or no treatment. ${ }^{136,137}$ Treatment of azospermic men with $\mathrm{rFSH}$ for 10 months prior to ICSI may lead to detection of sperms in the ejaculate and spare these men surgical sperm retrieval procedures. ${ }^{138}$ As age of the female partner is considered the single most important factor in predicting success of other interventions such as ICSI, the benefit of this relatively long period of treatment may need to be weighed up against the expected advancement in maternal age, especially in women above 35 .

There are few data on the use of lutropin alpha in male factor infertility. Due to its structural similarity, purified HCG may be an effective substitute for LH as the two hormones act through the same Leydig cell receptor. ${ }^{139}$ In normal men, a single IV injection of $150 \mathrm{IU}$ lutropin induces a $25 \%$ rise in plasma testosterone levels by comparison with placebo. ${ }^{140} \mathrm{We}$ are not aware of any published randomized trials investigating the effect of lutropin alpha for male factor infertility.

In males with hypogonadotrophic hypogonadism presented by azospermia or sever oligoasthenoteratospermia, $\mathrm{rFSH}$ may be effective in achieving spermatogenesis when combined with HCG. ${ }^{141-144}$ Combined analysis of data from four clinical trials shows that HCG and $\mathrm{rFSH}$ induced spermatogenesis in $84 \%$ of men with hypogonadotrophic hypogonadism. ${ }^{145} \mathrm{~A}$ number of baseline factors, including mean testicular volume, body mass index, age of disease onset and response to previous therapy, has been shown to influence the response. ${ }^{145,146}$

\section{Patient satisfaction}

Recombinant FSH can be used either as subcutaneous or intramuscular injection. Both follitropin alpha and beta are currently available in prefilled pen like devices for self injection. This delivery system has been shown to improve patient compliance and satisfaction..$^{82,147,148}$ A randomized trial comparing follitropin alpha in a pen device to the conventional syringe has shown that the former is associated with significantly higher rates of self-administration and satisfaction, with significantly less pain and local reactions at the injection site. ${ }^{149}$ A questionnaire based study on ease-of-use, safety and efficacy of two follitropin injection pens found the follitropin alpha pen to be effective, well tolerated with higher patient and nurse acceptance than the follitropin beta pen. ${ }^{150}$

\section{Economic evaluation}

A number of economic analyses comparing $\mathrm{rFSH}$ versus uHMG have been published. ${ }^{151-154}$ Two studies compared 


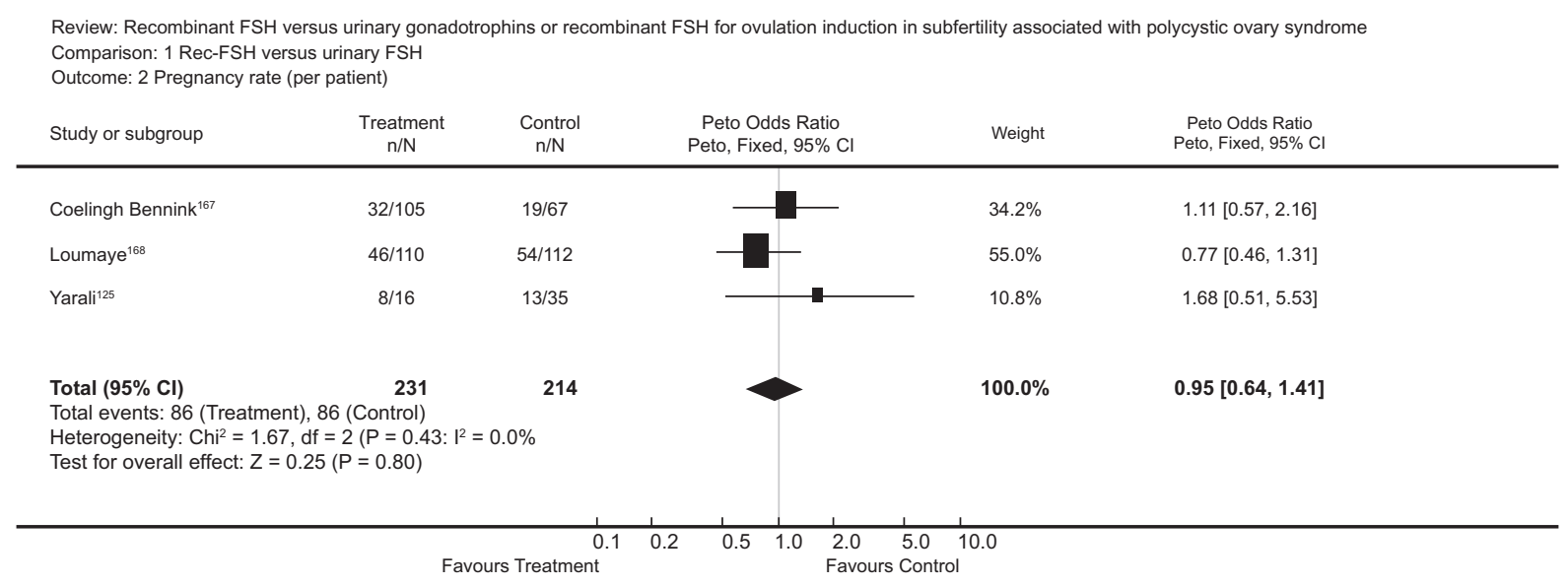

Figure 2 Meta-analysis of randomized trials of hMG versus $\mathrm{rFSH}$ for the outcome of pregnancy rate per patient in women undergoing ovulation induction for subfertility associated with polycystic ovarian syndrome. Bayram N, van Wely M, van Der Veen F. Recombinant FSH versus urinary gonadotrophins or recombinant FSH for ovulation induction in subfertility associated with polycystic ovary syndrome. Cochrane Database Syst Rev. 2001;2(2):CD002I $21 .{ }^{128}$ Copyright (C) Cochrane Collaboration, reproduced with permission. Abbreviations: HMG, human menopausal gonadotropin; RFSH, recombinant follicle stimulating hormone.

highly purified FSH with $\mathrm{rFSH} .{ }^{155,156}$ Results from these studies, which were supported directly or indirectly by pharmaceutical companies, were conflicting. One of these analyses ${ }^{156}$ was based on data from a large randomized trial comparing the use of HP HMG to rFSH in IVF treatment. ${ }^{73}$ The results have shown urine-derived highly purified HMG to be a cost-effective alternative to follitropin alpha. The median cost per live birth was significantly lower in the HP HMG group than in the $\mathrm{rFSH}$ group (£8893 and £11741, respectively, $P<0.001) .{ }^{156}$

An economic analysis based on data from a meta-analysis of 8 RCTs, comparing rFSH to uHMG, has estimated an average cost of an ongoing pregnancy at 13,946 Egyptian pounds (EGP) for a HMG cycle versus 18,721 (EGP) for a rFSH cycle. ${ }^{157,158}$ This economic analysis was based on the prices of $\mathrm{rFSH}$ and $\mathrm{uHMG}$ in the Egyptian market (150 Egyptian pounds for $75 \mathrm{IU} \mathrm{rFSH}$, and 50 Egyptian pounds for $75 \mathrm{IU}$ uHMG). The cost was calculated on the base of the fees charged by the authors' IVF center. Al-Inany et al showed that a $60 \%$ reduction in the cost of $\mathrm{rFSH}$ would be needed in order to provide a cost per ongoing IVF pregnancy similar to that achieved with uHMG. ${ }^{158}$ HMG use would result in 4565 more pregnancies in a hypothetical model based on 100,000 IVF cycles. Wechowski et al ${ }^{156}$ estimated that the savings associated with HP-HMG (as opposed to rFSH) would fund one additional IVF cycle in every 10 cycles while Lloyd et al ${ }^{155}$ projected a $13 \%$ increase in the number of cycles possible with the same budget. ${ }^{155,156}$

The use of uHMG for ovulation induction in anovulatory women can lead to $9.4 \%$ reduction in the cost per live birth. ${ }^{124}$
Two separate economic analyses have demonstrated that uHMG is more cost-effective than $\mathrm{rFSH}$ in superovulation with IUI. ${ }^{159,160}$

\section{Conclusion}

Follitropin alpha and lutropin alpha are human $\mathrm{rFSH}$ and $\mathrm{rLH}$, respectively. They are manufactured by genetic engineering techniques which ensure high quality and batch to batch consistency. Current evidence suggested superiority of uHMG over follitropin alpha in controlled ovarian hyperstimulation for IVF in terms of live birth rate per couple. Currently, there is no evidence to recommend the routine use of lutropin to follitropin alpha in an unselected IVF population. The use of follitropin alpha is comparable to HP FSH for ovulation induction in WHO group II anovulation. There is evidence that uHMG preparations (especially currently available highly purified preparations) are more cost effective than $\mathrm{rFSH}$ in terms of cost per ongoing pregnancy. However, patient satisfaction and quality of life in women using $\mathrm{rFSH}$ injection pen devices are higher than those using the conventional syringes for uHMG.

\section{Disclosures}

The authors declare no conflicts of interest.

\section{References}

1. Smith MG. On the interruption of pregnancy in the rat by the injection of ovarian follicular extract. Bull Johns Hopkins Hosp. 1926;39(4):203-214.

2. Fevold SL, Hisaw FL, Leonard SL. The gonad-stimulating and the luteinizing hormones of the anterior lobe of the hypophysis. Am J Physiol. 1931;97:291-301.

3. Lunenfeld B. Historical perspectives in gonadotrophin therapy. Hum Reprod Update. 2004;10(6):453-467. 
4. Gemzell CA, Diczfalusy E, Tillinger G. Clinical effect of human pituitary follicle-stimulating hormone (FSH). J Clin Endocrinol Metab. 1958;18(12):1333-1348.

5. Lunenfeld B. Development of gonadotrophins for clinical use. Reprod Biomed Online. 2002;4 Suppl:111-117.

6. Dumble LJ, Klein RD. Creutzfeldt-Jakob legacy for Australian women treated with human pituitary gonadotropins. Lancet. 1992;340(8823):847-848.

7. Cochius JI, Burns RJ, Blumbergs PC, Mack K, Alderman CP. Creutzfeldt-Jakob disease in a recipient of human pituitary-derived gonadotrophin. Aust NZ J Med. 1990;20(4):592-593.

8. Strowitzki T. Biotechnological drugs for reproductive disorders: a review of developments. BioDrugs. 1997;8(5):360-370.

9. Gordon K. New developments in gonadotrophin pharmacology. Reprod Biomed Online. 2002;5(3):259-264.

10. Giudice LC. Insulin-like growth factor family in Graafian follicle development and function. J Soc Gynecol Investig. 2001;8(1 Suppl Proceedings):S26-S29.

11. Wolfenson C, Groisman J, Couto AS, et al. Batch-to-batch consistency of human-derived gonadotrophin preparations compared with recombinant preparations. Reprod Biomed Online. 2005;10(4):442-454.

12. Howles CM. Genetic engineering of human FSH (Gonal-F). Hum Reprod Update. 1996;2(2):172-191.

13. Olijve W, de Boer W, Mulders JW, van Wezenbeek PM. Molecular biology and biochemistry of human recombinant follicle stimulating hormone (Puregon). Mol Hum Reprod. 1996;2(5):371-382.

14. Alper M, Meyer R, Dekkers C, Ezcurra D, Schertz J, Kelly E. Assessment of the biopotency of follitropin alfa and lutropin alfa combined in one injection: a comparative trial in Sprague-Dawley rats. Reprod Biol Endocrinol. 2008;6:31-36.

15. Saz-Parkinson Z, López-Cuadrado T, Bouza C, Amate JM. Outcomes of new quality standards of follitropin alfa on ovarian stimulation: meta-analysis of previous studies. BioDrugs. 2009;23(1):37-42.

16. Agostinetto R. Administration of follitropin alfa and lutropin alfa combined in a single injection: a feasibility assessment. Reprod Biol Endocrinol. 2009;7:48-52.

17. http://www.emea.europa.eu/humandocs/PDFs/EPAR/pergoveris/ H-714-en1.pdf

18. Pierce JG, Faith MR, Giudice LC, Reeve JR. Structure and structurefunction relationships in glycoprotein hormones. Ciba Found Symp. 1976;41:225-250.

19. Gordon K, Prins M, Schuller K, Lewin J. One million and counting. Reprod Biomed Online. 2006;13(3):313-314.

20. Goa KL, Wagstaff AJ. Follitropin alpha in infertility: a review. BioDrugs. 1998;9(3):235-260.

21. Wide L, Bakos O. More basic forms of both human follicle-stimulating hormone and luteinizing hormone in serum at midcycle compared with the follicular or luteal phase. J Clin Endocrinol Metab. 1993;76(4): 885-889.

22. Papandreou MJ, Asteria C, Pettersson K, Ronin C, Beck-Peccoz P. Concanavalin A affinity chromatography of human serum gonadotropins: evidence for changes of carbohydrate structure in different clinical conditions. J Clin Endocrinol Metab. 1993;76(4):1008-1013.

23. Green ED, Baenziger JU. Asparagine-linked oligosaccharides on lutropin, follitropin, and thyrotropin. II. Distributions of sulfated and sialylated oligosaccharides on bovine, ovine, and human pituitary glycoprotein hormones. J Biol Chem. 1988;263(1):36-44.

24. Dahl KD, Stone MP. FSH isoforms, radioimmunoassays, bioassays, and their significance. J Androl. 1992;13(1):11-22.

25. Andersen AN, Devroey P, Arce JC. Clinical outcome following stimulation with highly purified hMG or recombinant FSH in patients undergoing IVF: a randomized assessor-blind controlled trial. Hum Reprod. 2006;21(12):3217-3227.

26. Lambert A, Rodgers M, Mitchell R, et al. In-vitro biopotency and glycoform distribution of recombinant human follicle stimulating hormone (Org 32489), Metrodin and Metrodin-HP. Hum Reprod. 1995;10(7):1928-1935.
27. Mitchell R, Bauerfeld C, Schaefer F, Scharer K, Robertson WR. Less acidic forms of luteinizing hormone are associated with lower testosterone secretion in men on haemodialysis treatment. Clin Endocrinol (Oxf). 1994;41(1):65-73.

28. Chappel SC. Heterogeneity of follicle stimulating hormone: control and physiological function. Hum Reprod Update. 1995;5:479-487.

29. Zambrano E, Olivares A, Mendez JP, et al. Dynamics of basal and gonadotropin-releasing hormone-releasable serum follicle-stimulating hormone charge isoform distribution throughout the human menstrual cycle. J Clin Endocrinol Metab. 1995;80(5):1647-1656.

30. Anobile CJ, Talbot JA, McCann SJ, Padmanabhan V, Robertson WR. Glycoform composition of serum gonadotrophins through the normal menstrual cycle and in the post-menopausal state. Mol Hum Reprod. 1998;4(7):631-639.

31. Bishop LA, Nguyen TV, Schofield PR. Both of the beta-subunit carbohydrate residues of follicle-stimulating hormone determine the metabolic clearance rate and in vivo potency. Endocrinology. 1995;136(6):2635-2640.

32. Dhillon S, Keating GM. Lutropin alfa. Drugs. 2008;68(11):1529-1540.

33. Loumaye E, Engrand P, Howles CM, O'Dea L. Assessment of the role of serum luteinizing hormone and estradiol response to folliclestimulating hormone on in vitro fertilization treatment outcome. Fertil Steril. 1997;67(5):889-899.

34. Weston AM, Zelinski-Wooten MB, Hutchison JS, Stouffer RL, Wolf DP. Developmental potential of embryos produced by in-vitro fertilization from gonadotrophin-releasing hormone antagonist-treated macaques stimulated with recombinant human follicle stimulating hormone alone or in combination with luteinizing hormone. Hum Reprod. 1996;11(3):608-613.

35. Zelinski-Wooten MB, Hutchison JS, Hess DL, Wolf DP, Stouffer RL. Follicle stimulating hormone alone supports follicle growth and oocyte development in gonadotrophin-releasing hormone antagonist-treated monkeys. Hum Reprod. 1995;10(7):1658-1666.

36. Burgues S. Spanish Collaborative Group on Female Hypogonadotrophic Hypogonadism. The effectiveness and safety of recombinant human LH to support follicular development induced by recombinant human FSH in WHO group I anovulation: evidence from a multicentre study in Spain. Hum Reprod. 2001;16(12):2525-2532.

37. Recombinant LH Study Group. Does the addition of recombinant LH in WHO group II anovulatory women over-responding to FSH treatment reduce the number of developing follicles? A dose-finding study. Hum Reprod. 2005;20(3):629-635.

38. Loumaye E. Ovarian stimulation: is exogenous LH necessary in all patients? Gynecol Obstet Fertil. 2002;30(11):890-895.

39. Loumaye E, Engrand P, Shoham Z, Hillier SG, Baird DT. Clinical evidence for an LH ceiling? Hum Reprod. 2003;18(12):2719-2720.

40. Lockwood GM, Muttukrishna S, Groome NP, Knight PG, Ledger WL. Circulating inhibins and activin A during GnRH-analogue downregulation and ovarian hyperstimulation with recombinant FSH for in-vitro fertilization-embryo transfer. Clin Endocrinol (Oxf). 1996;45(6):741-748.

41. Fisch B, Avrech OM, Pinkas H, et al. Superovulation before IVF by recombinant versus urinary human FSH (combined with a long GnRH analog protocol): a comparative study. J Assist Reprod Genet. 1995;12(1):26-31.

42. le Cotonnec JY, Loumaye E, Porchet HC, Beltrami V, Munafo A. Pharmacokinetic and pharmacodynamic interactions between recombinant human luteinizing hormone and recombinant human follicle-stimulating hormone. Fertil Steril. 1998;69(2):201-209.

43. Karlsson MO, Wade JR, Loumaye E, Munafo A. The population pharmacokinetics of recombinant- and urinary-human follicle stimulating hormone in women. Br J Clin Pharmacol. 1998;45(1):13-20.

44. le Cotonnec JY, Porchet HC, Beltrami V, Munafo A. Clinical pharmacology of recombinant human luteinizing hormone: Part I. Pharmacokinetics after intravenous administration to healthy female volunteers and comparison with urinary human luteinizing hormone. Fertil Steril. 1998;69(2):189-194. 
45. le Cotonnec JY, Porchet HC, Beltrami V, Khan A, Toon S, Rowland M. Clinical pharmacology of recombinant human follicle-stimulating hormone (FSH). I. Comparative pharmacokinetics with urinary human FSH. Fertil Steril. 1994;61(4):669-678.

46. Baer G, Loumaye E. Comparison of recombinant human luteinising hormone (r-hLH) and human menopausal gonadotropin (hMG) in assisted reproductive technology. Curr Med Res Opin. 2003;19(2):83-88.

47. Siebold B. Physicochemical characterization of recombinant human follicle stimulating hormone. Hum Reprod. 1996;11 Suppl:1109-1115; discussion 117-119.

48. Driebergen R, Baer G. Quantification of follicle stimulating hormone (follitropin alfa): is in vivo bioassay still relevant in the recombinant age? Curr Med Res Opin. 2003;19(1):41-46.

49. Lispi M, Bassett R, Crisci C, et al. Comparative assessment of the consistency and quality of a highly purified FSH extracted from human urine (urofollitropin) and a recombinant human FSH (follitropin alpha). Reprod Biomed Online. 2006;13(2):179-193.

50. Lass A, McVeigh E; UK Gonal-f FbM PMS Group. Routine use of r-hFSH follitropin alfa filled-by-mass for follicular development for IVF: a large multicentre observational study in the UK. Reprod Biomed Online. 2004;9(6):604-610.

51. Wikland M, Hugues JN, Howles C. Improving the consistency of ovarian stimulation: follitropin alfa filled-by-mass. Reprod Biomed Online. 2006;12(6):663-668.

52. Keck C, Bassett R, Ludwig M. Factors influencing response to ovarian stimulation. Reprod Biomed Online. 2005;11(5):562-569.

53. http//www.fda.gov/cder/foi/label/2004/21322/lbl.pdf

54. Dickey RP. Strategies to reduce multiple pregnancies due to ovulation stimulation. Fertil Steril. 2009;91(1):1-17.

55. Van Loon K. Safety of high doses of recombinant human growth hormone. Horm Res. 1998;49(\# Suppl 2):78-81.

56. Hugues JN. Recombinant human follicle-stimulating hormone: a scientific step to clinical improvement. Reprod Biomed Online. 2001;2(1):54-64.

57. Recombinant Human FSH Study Group. Clinical assessment of recombinant human follicle-stimulating hormone in stimulating ovarian follicular development before in vitro fertilization. Fertil Steril. 1995;63(1):77-86.

58. Bergh C, Howles CM, Borg K, et al. Recombinant human follicle stimulating hormone (r-hFSH; Gonal-F) versus highly purified urinary FSH (Metrodin HP): results of a randomized comparative study in women undergoing assisted reproductive techniques. Hum Reprod. 1997;12(10):2133-2139.

59. Balen A, Platteau P, Andersen AN, Devroey P, Helmgaard L, Arce JC; for the Bravelle Ovulation Induction (BOI) Study Group. Highly purified FSH is as efficacious as recombinant FSH for ovulation induction in women with WHO Group II anovulatory infertility: a randomized controlled non-inferiority trial. Hum Reprod. 2007;22(7): 1816-1823.

60. Loret de Mola JR, Kiwi R, Austin C, Goldfarb JM. Subclavian deep vein thrombosis associated with the use of recombinant follicle-stimulating hormone (Gonal-F) complicating mild ovarian hyperstimulation syndrome. Fertil Steril. 2000;73(6):1253-1256.

61. Bar J, Orvieto R, Lahav J, Hod M, Kaplan B, Fisch B. Effect of urinary versus recombinant follicle-stimulating hormone on platelet function and other hemostatic variables in controlled ovarian hyperstimulation. Fertil Steril. 2004;82(6):1564-1569.

62. Hedon B, Hugues JN, Emperaire JC, et al. A comparative prospective study of a chronic low dose versus a conventional ovulation stimulation regimen using recombinant human follicle stimulating hormone in anovulatory infertile women. Hum Reprod. 1998;13(10):2688-2692.

63. Harrison S, WolfT, Abuzeid MI. Administration of recombinant follicle stimulating hormone in a woman with allergic reaction to menotropin: a case report. Gynecol Endocrinol. 2000;14(3):149-152.

64. Phipps WR, Holden D, Sheehan RK. Use of recombinant human follicle-stimulating hormone for in vitro fertilization-embryo transfer after severe systemic immunoglobulin E-mediated reaction to urofollitropin. Fertil Steril. 1996;66(1):148-150.
65. Brinsden P, Akagbosu F, Gibbons LM, et al. A comparison of the efficacy and tolerability of two recombinant human follicle-stimulating hormone preparations in patients undergoing in vitro fertilizationembryo transfer. Fertil Steril. 2000;73(1):114-116.

66. Orvieto R, Nahum R, Rabinson J, Ashkenazi J, Anteby EY, Meltcer S. Follitropin-alpha (Gonal-F) versus follitropin-beta (Puregon) in controlled ovarian hyperstimulation for in vitro fertilization: is there any difference? Fertil Steril. 2009;91(4 Suppl):1522-1525.

67. Fried G, Harlin J, Wramsby H. Recombinant FSH - clinical experience with two different preparations. Fertil Steril. 1998;70 Suppl 1:S112.

68. Egbase PE. Severe OHSS: how many cases are preventable? Hum Reprod. 2000;15(1):8-10.

69. Aboulghar M, Evers JH, Al-Inany H. Intravenous albumin for preventing severe ovarian hyperstimulation syndrome: a Cochrane review. Hum Reprod. 2002;17(12):3027-3032.

70. Buyalos RP, Lee CT. Polycystic ovary syndrome: pathophysiology and outcome with in vitro fertilization. Fertil Steril. 1996;65(1):1-10.

71. MacDougall MJ, Tan SL, Balen A, Jacobs HS. A controlled study comparing patients with and without polycystic ovaries undergoing in-vitro fertilization. Hum Reprod. 1993;8(2):233-237.

72. Forman RG, Frydman R, Egan D, Ross C, Barlow DH. Severe ovarian hyperstimulation syndrome using agonists of gonadotropin-releasing hormone for in vitro fertilization: a European series and a proposal for prevention. Fertil Steril. 1990;53(3):502-509.

73. Fauser BC,Van Heusden AM. Manipulation of human ovarian function: physiological concepts and clinical consequences. Endocr Rev. 1997;18(1):71-106.

74. Balasch J, Fabregues F, Penarrubia J, et al. Outcome from consecutive assisted reproduction cycles in patients treated with recombinant follitropin alfa filled-by-bioassay and those treated with recombinant follitropin alfa filled-by-mass. Reprod Biomed Online. 2004;8(4): 408-413.

75. Balasch J, Penarrubia J, Fabregues F, et al. Ovarian responses to recombinant FSH or HMG in normogonadotrophic women following pituitary desensitization by a depot $\mathrm{GnRH}$ agonist for assisted reproduction. Reprod Biomed Online. 2003;7(1):35-42.

76. European and Israeli Study Group on Highly Purified Menotropin versus Recombinant Follicle-Stimulating Hormone. Efficacy and safety of highly purified menotropin versus recombinant follicle-stimulating hormone in in vitro fertilization/intracytoplasmic sperm injection cycles: a randomized, comparative trial. Fertil Steril. 2002;78(3): 520-528.

77. Al-Inany HG, Abou-Setta AM, Aboulghar MA, Mansour RT, Serour GI. Efficacy and safety of human menopausal gonadotrophins versus recombinant FSH: a meta-analysis. Reprod Biomed Online. 2008;16(1):81-88.

78. Coomarasamy A, Afnan M, Cheema D, van der Veen F, Bossuyt PM, van Wely M. Urinary hMG versus recombinant FSH for controlled ovarian hyperstimulation following an agonist long down-regulation protocol in IVF or ICSI treatment: a systematic review and metaanalysis. Hum Reprod. 2008;23(2):310-315.

79. Mochtar MH, Van der V, Ziech M, van Wely M. Recombinant Luteinizing Hormone (rLH) for controlled ovarian hyperstimulation in assisted reproductive cycles. Cochrane Database Syst Rev. 2007;2: CD005070.

80. Timeva T, Milachich T, Antonova I, Arabaji T, Shterev A, Omar HA. Correlation between number of retrieved oocytes and pregnancy rate after in vitro fertilization/intracytoplasmic sperm infection. Scientific WorldJournal. 2006;6686-690.

81. van Rumste MM, Custers IM, van der Veen F, van Wely M, Evers JL, Mol BW. The influence of the number of follicles on pregnancy rates in intrauterine insemination with ovarian stimulation: a meta-analysis. Hum Reprod Update. 2008;14(6):563-570.

82. Sedbon E, Wainer R, Perves C. Quality of life of patients undergoing ovarian stimulation with injectable drugs in relation to medical practice in France. Reprod Biomed Online. 2006;12(3):298-303.

83. Palermo R. Differential actions of FSH and LH during folliculogenesis. Reprod Biomed Online. 2007;15(3):326-337. 
84. O'Dea L, O'Brien F, Currie K, Hemsey G. Follicular development induced by recombinant luteinizing hormone (LH) and folliclestimulating hormone (FSH) in anovulatory women with $\mathrm{LH}$ and FSH deficiency: evidence of a threshold effect. Curr Med Res Opin. 2008;24(10):2785-2793.

85. Kliesch S, Behre HM, Nieschlag E. Recombinant human folliclestimulating hormone and human chorionic gonadotropin for induction of spermatogenesis in a hypogonadotropic male. Fertil Steril. 1995;63(6):1326-1328

86. Arslan AA, Gu Y, Zeleniuch-Jacquotte A, et al. Reproducibility of serum pituitary hormones in women. Cancer Epidemiol Biomarkers Prev. 2008;17(8):1880-1883.

87. Dhont M, Onghena A, Coetsier T, De Sutter P. Prospective randomized study of clomiphene citrate and gonadotrophins versus goserelin and gonadotrophins for follicular stimulation in assisted reproduction. Hum Reprod. 1995;10(4):791-796.

88. Steures P, van der Steeg JW, Hompes PG, et al. Intra-uterine insemination with controlled ovarian hyperstimulation compared to an expectant management in couples with unexplained subfertility and an intermediate prognosis: a randomised study. Ned Tijdschr Geneeskd. 2008;152(27):1525-1531.

89. Bensdorp AJ, Cohlen BJ, Heineman MJ, Vandekerckhove P. Intrauterine insemination for male subfertility. Cochrane Database Syst Rev. 2007;4(4):CD000360.

90. Barlow DH. GnRH agonists and in vitro fertilization. J Reprod Med. 1998;43(3 Suppl):245-251.

91. Sbracia M, Colabianchi J, Giallonardo A, et al. Cetrorelix protocol versus gonadotropin-releasing hormone analog suppression long protocol for superovulation in intracytoplasmic sperm injection patients older than 40. Fertil Steril. 2009;91(5):1842-1847.

92. Coccia ME, Comparetto C, Bracco GL, Scarselli G. GnRH antagonists. Eur J Obstet Gynecol Reprod Biol. 2004;115 Supp1 1:S44-S56.

93. Kingsland C, Tan SL, Bickerton N, Mason B, Campbell S. The routine use of gonadotropin-releasing hormone agonists for all patients undergoing in vitro fertilization. Is there any medical advantage? A prospective randomized study. Fertil Steril. 1992;57(4):804-809.

94. Broekmans FJ, Bernardus RE, Berkhout G, Schoemaker J. Pituitary and ovarian suppression after early follicular and mid-luteal administration of a LHRH agonist in a depot formulation: decapeptyl CR Gynecol Endocrinol. 1992;6(3):153-161.

95. Abdalla HI, Ahuja KK, Leonard T, Morris NN, Honour JW, Jacobs HS. Comparative trial of luteinizing hormone-releasing hormone analog/ human menopausal gonadotropin and clomiphene citrate/human menopausal gonadotropin in an assisted conception program. Fertil Steril. 1990;53(3):473-478.

96. De Placido G, Alviggi C, Mollo A, Strina I, Varricchio MT, Molis M. Recombinant follicle stimulating hormone is effective in poor responders to highly purified follicle stimulating hormone. Hum Reprod. 2000;15(1):17-20.

97. Mohamed MA, Sbracia M, PacchiarottiA, et al. Urinary follicle-stimulating hormone (FSH) is more effective than recombinant FSH in older women in a controlled randomized study. Fertil Steril. 2006;85(5):1398-1403.

98. Hompes PG, Broekmans FJ, Hoozemans DA, Schats R, FIRM group. Effectiveness of highly purified human menopausal gonadotropin vs recombinant follicle-stimulating hormone in first-cycle in vitro fertilization-intracytoplasmic sperm injection patients. Fertil Steril. 2008;89(6):1685-1693.

99. Bosch E, Vidal C, Labarta E, Simon C, Remohi J, Pellicer A. Highly purified hMG versus recombinant FSH in ovarian hyperstimulation with GnRH antagonists - a randomized study. Hum Reprod. 2008;23(10):2346-2351.

100. Shoham Z, Insler V. Recombinant technique and gonadotropins production: new era in reproductive medicine. Fertil Steril. 1996;66(2):187-201.

101. Tulppala M, Aho M, Tuuri T, et al. Comparison of two recombinant follicle-stimulating hormone preparations in in-vitro fertilization: a randomized clinical study. Hum Reprod. 1999;14(11):2709-2715.
102. Harlin J, Csemiczky G, Wramsby H, Fried G. Recombinant follicle stimulating hormone in in-vitro fertilization treatment-clinical experience with follitropin alpha and follitropin beta. Hum Reprod. 2000;15(2):239-244.

103. Platteau P, Andersen AN, Balen A, et al; Menopur Ovulation Induction (MOI) Study Group. Similar ovulation rates, but different follicular development with highly purified menotrophin compared with recombinant FSH in WHO Group II anovulatory infertility: a randomized controlled study. Hum Reprod. 2006;21(7): 1798-1804.

104. Kolibianakis E, Zikopoulos K, Albano C, et al. Reproductive outcome of polycystic ovarian syndrome patients treated with GnRH antagonists and recombinant FSH for IVF/ICSI. Reprod Biomed Online. 2003;7(3):313-318.

105. Watson H, Kiddy DS, Hamilton-Fairley D, et al. Hypersecretion of luteinizing hormone and ovarian steroids in women with recurrent early miscarriage. Hum Reprod. 1993;8(6):829-833.

106. Oliveira JB, Mauri AL, Petersen CG, et al. Recombinant luteinizing hormone supplementation to recombinant follicle-stimulation hormone during induced ovarian stimulation in the GnRH-agonist protocol: a meta-analysis. J Assist Reprod Genet. 2007;24(2-3): 67-75.

107. Barrenetxea G, Agirregoikoa JA, Jimenez MR, de Larruzea AL, Ganzabal T, Carbonero K. Ovarian response and pregnancy outcome in poor-responder women: a randomized controlled trial on the effect of luteinizing hormone supplementation on in vitro fertilization cycles. Fertil Steril. 2008;89(3):546-553.

108. Kolibianakis EM, Kalogeropoulou L, Griesinger G, et al. Among patients treated with FSH and GnRH analogues for in vitro fertilization, is the addition of recombinant $\mathrm{LH}$ associated with the probability of live birth? A systematic review and meta-analysis. Hum Reprod Update. 2007;13(5):445-452.

109. Durnerin CI, Erb K, Fleming R, et al; Luveris Pretreatment Group. Effects of recombinant $\mathrm{LH}$ treatment on folliculogenesis and responsiveness to FSH stimulation. Hum Reprod. 2008;23(2):421-426.

110. Picard M, Rossier C, Papasouliotis O, Lugan I. Bioequivalence of recombinant human $\mathrm{FSH}$ and recombinant human $\mathrm{LH}$ in a fixed 2:1 combination: two phase I, randomised, crossover studies. Curr Med Res Opin. 2008;24(4):1199-1208.

111. Lachelin GC, Yen SS. Hypothalamic chronic anovulation. Am JObstet Gynecol. 1978;130(7):825-831.

112. Homburg R. Ovulation induction. Expert Opin Pharmacother. 2003;4(11):1995-2004.

113. Filicori M, Flamigni C, Cognigni G, Dellai P, Michelacci L, Arnone R. Increased insulin secretion in patients with multifollicular and polycystic ovaries and its impact on ovulation induction. Fertil Steril. 1994;62(2):279-285.

114. The ESHRE Capri Workshop Group. Anovulatory infertility. Hum Reprod. 1995;10(6):1549-1553.

115. Shoham Z, Smith H, Yeko T, O’Brien F, Hemsey G, O’Dea L. Recombinant LH (lutropin alfa) for the treatment of hypogonadotrophic women with profound LH deficiency: a randomized, double-blind, placebo-controlled, proof-of-efficacy study. Clin Endocrinol (Oxf). 2008;69(3):471-478.

116. Kaufmann R, Dunn R, Vaughn T, et al. Recombinant human luteinizing hormone, lutropin alfa, for the induction of follicular development and pregnancy in profoundly gonadotrophin-deficient women. Clin Endocrinol (Oxf). 2007;67(4):563-569.

117. Kousta E, White DM, Piazzi A, Loumaye E, Franks S. Successful induction ovulation and completed pregnancy using recombinant human luteinizing hormone and follicle stimulating hormone in a woman with Kallmann's syndrome. Hum Reprod. 1996;11(1):70-71.

118. Campo S, Campo V, Lanzone A. Twin pregnancy using recombinant gonadotropins in a woman with hypogonadotropic hypogonadism. Gynecol Endocrinol. 2002;16(1):27-32.

119. Broekmans FJ,Fauser BC. Diagnostic criteria for polycystic ovarian syndrome. Endocrine. 2006;30(1):3-11. 
120. Rotterdam ESHRE/ASRM-Sponsored PCOS Consensus Workshop Group. Revised 2003 consensus on diagnostic criteria and longterm health risks related to polycystic ovary syndrome. Fertil Steril. 2004;81(1):19-25.

121. Hendriks ML, Brouwer J, Hompes PG, Homburg R, Lambalk CB. $\mathrm{LH}$ as a diagnostic criterion for polycystic ovary syndrome in patients with WHO II oligo/amenorrhoea. Reprod Biomed Online. 2008; 16(6):765-771.

122. Donderwinkel PF, Schoot DC, Coelingh Bennink HJ, Fauser BC. Pregnancy after induction of ovulation with recombinant human FSH in polycystic ovary syndrome. Lancet. 1992;340(8825):983.

123. Platteau P, Andersen AN, Balen A, et al. Ovulation Induction (MOI) Study Group. Similar ovulation rates, but different follicular development with highly purified menotrophin compared with recombinant FSH in WHO Group II anovulatory infertility: a randomized controlled study. Hum Reprod. 2006;21(7):1798-1804.

124. Revelli A, Poso F, Gennarelli G, Moffa F, Grassi G, Massobrio M. Recombinant versus highly-purified, urinary follicle-stimulating hormone (r-FSH vs $\mathrm{HP}-\mathrm{uFSH}$ ) in ovulation induction: a prospective, randomized study with cost-minimization analysis. Reprod Biol Endocrinol. 2006;4:38.

125. Yarali $\mathrm{H}$, Bukulmez $\mathrm{O}$, Gurgan T. Urinary follicle-stimulating hormone (FSH) versus recombinant FSH in clomiphene citrate-resistant, normogonadotropic,chronic anovulation: a prospective randomized study. Fertil Steril. 1999;72(2):276-281.

126. Yarali $\mathrm{H}, \mathrm{Zeyneloglu} \mathrm{HB}$. Gonadotrophin treatment in patients with polycystic ovary syndrome. Reprod Biomed Online. 2004;8(5):528-537.

127. Fulghesu AM, Apa R, Belosi C, et al. Recombinant versus urinary follicle-stimulating hormone in the low-dose regimen in anovulatory patients with polycystic ovary syndrome: a safer and more effective treatment. Horm Res. 2001;55(5):224-228.

128. Bayram N, van Wely M, van Der Veen F. Recombinant FSH versus urinary gonadotrophins or recombinant FSH for ovulation induction in subfertility associated with polycystic ovary syndrome. Cochrane Database Syst Rev. 2001;2(2):CD002121.

129. Lopez E, Gunby J, Daya S, Parrilla JJ, Abad L, Balasch J. Ovulation induction in women with polycystic ovary syndrome: randomized trial of clomiphene citrate versus low-dose recombinant FSH as first line therapy. Reprod Biomed Online. 2004;9(4):382-390.

130. Szilagyi A, Bartfai G, Manfai A, Koloszar S, Pal A, Szabo I. Low-dose ovulation induction with urinary gonadotropins or recombinant follicle stimulating hormone in patients with polycystic ovary syndrome. Gynecol Endocrinol. 2004;18(1):17-22.

131. Cristello F, Cela V, Artini PG, Genazzani AR. Therapeutic strategies for ovulation induction in infertile women with polycystic ovary syndrome. Gynecol Endocrinol. 2005;21(6):340-352.

132. Leader A; Monofollicular Ovulation Induction Study Group. Improved monofollicular ovulation in anovulatory or oligo-ovulatory women after a low-dose step-up protocol with weekly increments of 25 international units of follicle-stimulating hormone. Fertil Steril. 2006;85(6):1766-1773.

133. Attia AM, Al-Inany HG. Gonadotrophins for idiopathic male factor subfertility. Cochrane Database Syst Rev. 2007;(4)(4):CD005071.

134. McLachlan RI. The endocrine control of spermatogenesis. Baillieres Best Pract Res Clin Endocrinol Metab. 2000;14(3):345-362.

135. Miyagawa Y, Tsujimura A, Matsumiya K, Takao T, Tohda A, Koga M, et al. Outcome of gonadotropin therapy for male hypogonadotropic hypogonadism at university affiliated male infertility centers: a 30-year retrospective study. J Urol. 2005;173:2072-2075.

136. Kamischke A, Behre HM, Bergmann M, Simoni M, Schafer T, Nieschlag E. Recombinant human follicle stimulating hormone for treatment of male idiopathic infertility: a randomized, double-blind, placebo-controlled, clinical trial. Hum Reprod. 1998;13(3):596-603.

137. Foresta C, Selice R, Ferlin A, Garolla A. Recombinant FSH in the treatment of oligozoospermia. Expert Opin Biol Ther. 2009;9(5):659-666.

138. Bakircioglu ME, Erden HF, Ciray HN, Bayazit N, Bahceci M. Gonadotrophin therapy in combination with ICSI in men with hypogonadotrophic hypogonadism. Reprod Biomed Online. 2007;15(2):156-160.
139. Lee KH, Diekman MA, Moss GE, Allrich RD. Pituitary gonadotropins, hypothalamic gonadotropin-releasing hormone, and testicular traits of boars exposed to natural or supplemental lighting during pubertal development. Biol Reprod. 1987;36(5):1164-1169.

140. Cailleux-Bounacer A, Reznik Y, Cauliez B, Menard JF, Duparc C, Kuhn JM. Evaluation of endocrine testing of Leydig cell function using extractive and recombinant human chorionic gonadotropin and different doses of recombinant human LH in normal men. Eur $J$ Endocrinol. 2008;159(2):171-178.

141. Bouloux P, Warne DW, Loumaye E. Efficacy and safety of recombinant human follicle-stimulating hormone in men with isolated hypogonadotrophic hypogonadism. Fertil Steril. 2002;77:270-273.

142. Liu PY, Turner L, Rushford D, McDonald J, Baker HW, Conway AJ, et al. Efficacy and safety of recombinant human follicle stimulating hormone (Gonal-F) with urinary human chorionic gonadotrophin for induction of spermatogenesis and fertility in gonadotrophin-deficient men. Hum Reprod. 1999;14:1540-1545.

143. Matsumoto AM, Snyder P, Bhasin S, Martin K, Weber T,Winters S, et al. Stimulation of spermatogenesis with recombinant human folliclestimulating hormone (follitropin alfa; GONAL-f) long-term treatment in azoospermic men with hypogonadotropic hypogonadism $(\mathrm{HH})$. Fertil Steril. 2008. [Epub ahead of print]

144. Okada $\mathrm{H}$, on behalf of the Japanese MHH study group. Recombinant human follicle-stimulating hormone (r-hFSH, follitropin alfa) is efficacious for induction of spermatogenesis and pregnancy in Japanese men with hypogonadotropic hypogonadism. Fertil Steril. 2005; 84(Supp1 1):S222.

145. Warne D, Okada H, Yano Y, Koide N, Howles C. A combined analysis of data to identify predictive factors for spermatogenesis in men with hypogonadotropic hypogonadism treated with recombinant human follicle-stimulating hormone and human chorionic gonadotropin. Fertil Steril. In press 2009.

146. Liu PY, Gebski VJ, Turner L, Conway AJ, Wishart SM, Handelsman DJ. Predicting pregnancy and spermatogenesis by survival analysis during gonadotrophin treatment of gonadotrophin-deficient infertile men. Hum Reprod. 2002;17:625-633.

147. Pang S, Kaplan B, Karande V, et al; Follistim Pen Trade Mark COH Study Group. Administration of recombinant human FSH (solution in cartridge) with a pen device in women undergoing ovarian stimulation. Reprod Biomed Online. 2003;7(3):319-326.

148. Pang SC.A pen injection device for self-administration of recombinant follicle-stimulating hormone for fertility treatments. Expert Rev Med Devices. 2005;2(1):27-32.

149. Aghssa MM, Azargoon A, Ramezanzadeh F, Bagheri M. A comparison of the efficacy, tolerability, and convenience of two formulations of follitropin-alpha in Iranian woman undergoing intracytoplasmic sperm injection cycles. Fertil Steril. 2008;90(4):1043-1048.

150. Porter R, Kissel C, Saunders H, Keck C. Patient and nurse evaluation of recombinant human follicle-stimulating hormone administration methods: comparison of two follitropin injection pens. Curr Med Res Opin. 2008;24(3):727-735.

151. Daya S, Ledger W, Auray JP, et al. Cost-effectiveness modelling of recombinant FSH versus urinary FSH in assisted reproduction techniques in the UK. Hum Reprod. 2001;16(12):2563-2569.

152. Hatoum HT, Keye WR Jr, Marrs RP, Walton SM, Marshall DC. A Markov model of the cost-effectiveness of human-derived folliclestimulating hormone (FSH) versus recombinant FSH using comparative clinical trial data. Fertil Steril. 2005;83(3):804-807.

153. Sykes D, Out HJ, Palmer SJ, van Loon J. The cost-effectiveness of IVF in the UK: a comparison of three gonadotrophin treatments. Hum Reprod. 2001;16(12):2557-2562.

154. Foresta C, Selice R, Ferlin A, Garolla A. Recombinant FSH in the treatment of oligozoospermia. Expert Opin Biol Ther. 2009;9(5):659-666.

155. Lloyd A, Kennedy R, Hutchinson J, Sawyer W. Economic evaluation of highly purified menotropin compared with recombinant follicle-stimulating hormone in assisted reproduction. Fertil Steril. 2003;80(5):1108-1113. 
156. Wechowski J, Connolly M, McEwan P, Kennedy R. An economic evaluation of highly purified HMG and recombinant FSH based on a large randomized trial. Reprod Biomed Online. 2007;15(5):500-506.

157. Al-Inany H, Aboulghar MA, Mansour RT, Proctor M. Recombinant versus urinary gonadotrophins for triggering ovulation in assisted conception. Hum Reprod. 2005;20(8):2061-2073.

158. Al-Inany HG, Abou-Setta AM, Aboulghar MA, Mansour RT, Serour GI. HMG versus rFSH for ovulation induction in developing countries: a cost-effectiveness analysis based on the results of a recent meta-analysis. Reprod Biomed Online. 2006;12(2):163-169.

159. Gerli S, Casini ML, Unfer V, Costabile L, Bini V, Di Renzo GC. Recombinant versus urinary follicle-stimulating hormone in intrauterine insemination cycles: a prospective, randomized analysis of cost effectiveness. Fertil Steril. 2004;82(3):573-578.

160. Gerli S, Bini V, Di Renzo GC. Cost-effectiveness of recombinant follicle-stimulating hormone (FSH) versus human $\mathrm{FSH}$ in intrauterine insemination cycles: a statistical model-derived analysis. Gynecol Endocrinol. 2008;24(1):18-23.

161. Shetty A. Disorders of ovulation. In: Templeton AA. ed. Management of Infertility for the MRCOG and Beyond. London: RCOG press; 2001.

162. Westergaard LG, Erb K, Laursen SB, Rex S, Rasmussen PE. Human menopausal gonadotropin versus recombinant follicle-stimulating hormone in normogonadotropic women down-regulated with a gonadotropin-releasing hormone agonist who were undergoing in vitro fertilization and intracytoplasmic sperm injection: a prospective randomized study. Fertil Steril. 2001;76(3):543-549.
163. $\mathrm{Ng} \mathrm{EH,} \mathrm{Lau} \mathrm{EY,} \mathrm{Yeung} \mathrm{WS,} \mathrm{Ho} \mathrm{PC.} \mathrm{HMG} \mathrm{is} \mathrm{as} \mathrm{good} \mathrm{as} \mathrm{recombinant}$ human FSH in terms of oocyte and embryo quality: a prospective randomized trial. Hum Reprod. 2001;16(2):319-325.

164. Gordon UD, Harrison RF, Fawzy M, Hennelly B, Gordon AC. A randomized prospective assessor-blind evaluation of luteinizing hormone dosage and in vitro fertilization outcome. Fertil Steril. 2001;75(2):324-331.

165. Kilani Z, Dakkak A, Ghunaim S, et al. A prospective, randomized, controlled trial comparing highly purified hMG with recombinant FSH in women undergoing ICSI: ovarian response and clinical outcomes. Hum Reprod. 2003;18(6):1194-1199.

166. Nyboe Andersen A, Devroey P, Arce J-C, for the MERIT Group. Clinical outcome following stimulation with highly purified hMG or recombinant FSH in patients undergoing IVF: a randomized assessor-blind controlled trial. Hum Reprod. 2006;21(12): 3217-3227.

167. Coelingh Bennink HJ, Fauser BC, Out HJ. Recombinant folliclestimulating hormone (FSH; Puregon) is more efficient than urinary FSH (Metrodin) in women with clomiphene citrate-resistant, normogonadotropic, chronic anovulation: a prospective, multicenter, assessor-blind, randomized, clinical trial. European Puregon Collaborative Anovulation Study Group. Fertil Steril. 1998;69(1):1925.

168. Loumaye E, Martineau I, Piazzi A, et al. Clinical assessment of human gonadotrophins produced by recombinant DNA technology. Hum Reprod. 1996;11 Suppl 195-107; discussion 117-119.
Biologics: Targets \& Therapy

\section{Publish your work in this journal}

Biologics: Targets \& Therapy is an international, peer-reviewed journal focusing on the patho-physiological rationale for and clinical application of Biologic agents in the management of autoimmune diseases, cancers or other pathologies where a molecular target can be identified. This journal is indexed on PubMed Central, CAS,

\section{Dovepress}

EMBase, Scopus and the Elsevier Bibliographic databases. The manuscript management system is completely online and includes a very quick and fair peer-review system, which is all easy to use. Visit http://www.dovepress.com/testimonials.php to read real quotes from published authors. 